\title{
Impact of Helicobacter pylori Infection on Serum Lipid Profile and Atherosclerosis of Carotid Artery
}

\author{
Hadeel A. Ibrahim ${ }^{1}$, Mohammed O. Mohammed ${ }^{2}$, Hawa A. R. Dhahir ${ }^{3}$, Kawa A. Mahmood4, \\ Bryar E. Nuradeen ${ }^{5}$ \\ ${ }^{1}$ Department of Physiology, School of Nursing, University of Sulaimani, Sulaimani, Iraq \\ ${ }^{2}$ Department of Internal Medicine, School of Medicine, University of Sulaimani, Sulaimani, Iraq \\ ${ }^{3}$ Department of Physiology, School of Medicine, University of Baghdad, Baghdad, Iraq \\ ${ }^{4}$ Department of Radiology, School of Medicine, University of Sulaimani, Sulaimani, Iraq \\ ${ }^{5}$ Sulaimani Central Laboratory, Sulaimani, Iraq \\ Email: ${ }^{*}$ dr_m_omer@yahoo.com
}

Received 20 June 2014; revised 18 July 2014; accepted 10 August 2014

Copyright (C) 2014 by authors and Scientific Research Publishing Inc.

This work is licensed under the Creative Commons Attribution International License (CC BY).

http://creativecommons.org/licenses/by/4.0/

(c) $\underset{\mathrm{EY}}{\mathrm{B}}$ Open Access

\section{Abstract}

Background: Helicobacter pylori (H. pylori) infection has been suggested to be associated with atherosclerosis. The issue is still controversial. It is well known that abnormal lipid profile is related to atherosclerosis and measurement of carotid intima-media thickness. Aim of the study: to investigate carotid intima-media thickness and lipid parameters in $H$. pylori-positive and -negative subjects. Materials \& Methods: This study was conducted in Kurdistan Teaching center of Gastroenterology and Hepatology (KCGH) in Sulaimani city during the period of December 2012 to March 2014. One hundred dyspeptic patients with $H$. pylori infection and 74 apparently healthy asymptomatic volunteers with $H$. pylori-negative tests were enrolled in this study. Both groups were comparable in age distribution and gender. $H$. pylori infection (IgG \& IgA) were assessed by ELISA tests, Triglyceride, total cholesterol, low-density lipoprotein cholesterol (LDL-C) and high-density lipoprotein cholesterol (HDL-C) concentrations were measured by routine enzymatic methods using commercial kits. Carotid intima-media thickness was assessed by high-resolution ultrasound. Results: The mean and maximum values of internal and common carotid intima-media thickness in $H$. pylori-positive subjects were significantly thicker than in $H$. pylori-negative subjects $(p<0.05)$. HDL-C level was lower in patients $(H$. pylori seropositive) than in controls (seronegative subjects), total cholesterol, LDL-C and triglyceride level were found to be higher in patients than in controls $(p<0.01)$. Conclusions: Carotid intima-media thickness as well as all lipid values apart from HDL-C was increased in $H$. pylori-positive subjects. These data indicated that $H$.

\footnotetext{
${ }^{*}$ Corresponding author.
} 
pylori infection may had a role in atherosclerotic process.

Keywords

Dyspepsia, H. pylori, Lipid Profile, Atherosclerosis

\section{Introduction}

Atherosclerosis is a multifactorial disease whose age of onset and progression are strongly influenced by inborn and acquired risk factors [1]. Many studies showed that $80 \%-90 \%$ of patients who developed clinically significant coronary artery disease (CAD) had at least one of four classical risk factors: hypercholesterolemia, hypertension, diabetes mellitus or smoking [2].

Carotid artery intima-media thickness (CIMT) is now widely used as an early marker for atherosclerotic disease [3]. The intima-media thickness of the common carotid artery (CCA) is thought to be associated with risk factors for stroke.

Atherosclerosis is an inflammatory disease and an association may exist between its development and infection with certain microorganisms [4]. Several studies have suggested that $H$. pylori infection can be involved in the pathogenesis of cardiovascular disease [5] [6]. Some studies have shown a positive correlation between $H$. pylori infection and the risk of cardiovascular disease [7] [8], whereas others have not confirmed such findings [9].

So the aim of this study was to investigate carotid intima-media thickness and lipid parameters in $H$. pyloripositive and -negative subjects.

\section{Materials and Methods}

This study was conducted in Kurdistan Teaching center of Gastroenterology and Hepatology (KCGH) in Sulaimani city during the period of December 2012 to March 2014. One hundred dyspeptic patients with $H$. pylori infection positive and 74 apparently healthy asymptomatic volunteers with $H$. pylori negative tests were enrolled in this study. Both groups were comparable in age distribution and gender.

\subsection{Exclusion Criteria}

1 -Pregnant women.

2-Patients previously treated for $H$. pylori infection.

3-Who had received antibiotics; proton pump inhibitors or bismuth compounds in the preceding 4 weeks.

This study was approved by the Ethics Committee for Analysis of Research Projects of Faculty of Medicine, University of Sulaimani and Directory of Health in Sulaimani. Written informed consent was obtained from the patients prior to study participation.

A form designed to collect demographic data: name, age, gender, chief compliant of patients and duration of illness. Ten ml venous blood aspirated after overnight fasting then centrifuged at $5000 \mathrm{r} / \mathrm{min}$ for $5 \mathrm{~min}$. Sera were tested for $H$. pylori IgG \& IgA antibodies at Sulaimani Central lab., using ELISA tests (Nova Lisa, NovaTec, Germany), according to the standard operating procedures. That has a sensitivity of $97 \%$ and a specificity of $98.8 \%$. Triglyceride, total cholesterol, low-density lipoprotein cholesterol (LDL-C) and high-density lipoprotein cholesterol (HDL-C) concentrations were measured by routine enzymatic methods using commercial kits (Elab Science, Germany).

Subjects were evaluated for both internal carotid (IC) and common carotid (CC) arteries and plaque occurrence by using high resolution grey-scale Doppler ultrasonography: Philips, En visor, Version C.1.3, 2007. In a semi-dark room, the subject lay supine with slightly hyper extended neck and rotated away from the imaging transducer. Both carotid arteries were scanned. CIMT was defined as the distance between the leading edge of the lumen intimal interface and the leading edge of the media adventitia interface of the far wall (3) Figure 1.

\subsection{Statistical Analysis}

All data were analyzed using Excel and SPSS (Version 20 software) computer program. Statistical analysis 


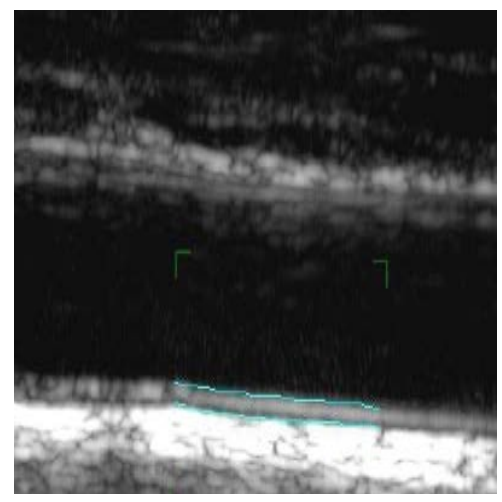

(a)

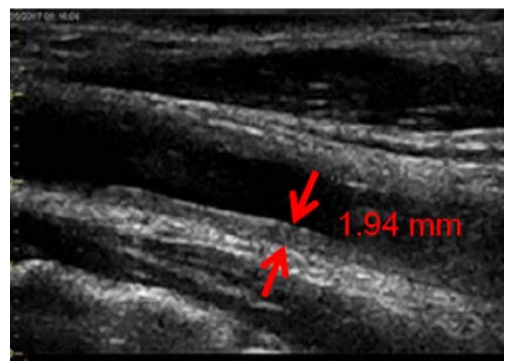

(b)

Figure 1. (a) Carotid intima-media thickness measurement in control group; (b) Carotid intima-media thickness measurement in patients.

included descriptive statistics like: a frequency, distribution tables, and correlation coefficient analysis. To assess the correlation between different variables, bivariate correlation coefficient analysis was performed. In this analysis, the statistical significant association was determined. All $\mathrm{p}$ values were based on 2-sided tests and $\mathrm{p}<$ 0.05 was considered statistically significant.

\section{Results}

Both groups of $\mathrm{H}$. pylori seropositive and seronegative groups were comparable in mean age and gender, Table 1 .

Both H. Pylori IgG and IgA levels were statistically higher in the patients group compared to the control group $(\mathrm{p}<0.01)$ as shown in Table 2 .

Significant differences were found between patients and controls in the levels of all lipid profile, $(\mathrm{p}<0.01)$ as revealed by Table 3 .

The intima-media thickness of both CCA and ICA was significantly higher in patients than in controls as shown in Table 4.

There was significant correlation between H. Pylori IgG concentration and total cholesterol, LDL-C level and inverse correlation with HDL-C level decreased; No significant correlation between H. Pylori IgG concentration and TG level; Also highly significant correlation between H. Pylori IgG level and carotid thickness ( $\mathrm{p}<0.01)$, Table 5.

\section{Discussion}

Some studies have demonstrated a relationship between $H$. pylori infection and extra digestive_tract disease [5] [6]. In this respect, cardiovascular disease is one of the most important diseases suggested to be related to infection which may be due to effect of infection on lipid metabolism [10]-[12].

Pellicano et al. reported significantly higher prevalence of $H$. pylori infection in patients with CAD than in controls (77\% vs. 59\%) [13]. Although these studies have suggested a relationship between $H$. pylori infection and coronary heart disease; some of the underlying mechanisms still need to be discovered. It has been reported that chronic $H$. pylori infection results in decreased HDL-C levels and these lipid alterations could, partially contribute to the initiation and development of coronary atherosclerosis [14] [15]. Infection and inflammation are associated with a decrease in HDL-C levels.

Major risk factors of atherosclerosis may explain only $50 \%$ of its etiology. Therefore, looking for new risk factors of atherosclerosis is necessary. HDL-C is a well known parameter inversely related to the risk for cardiovascular disease (CVD). It plays a key role in the reverse cholesterol transport, protects LDL against oxidation and reduces lipoprotein associated peroxides [16].

In the present study, HDL-C level was significantly lower in patients (H. pylori seropositive) than in controls (seronegative subjects), total cholesterol, LDL-C and triglyceride level were found to be significantly higher in patients than in controls $(\mathrm{P}<0.01)$. Concerning the changes in serum lipids in seropositive subjects, the results of our study were similar to other studies [14] [17]-[21]. Buzás reported that the increase of cholesterol and 
Table 1. Characteristics of patients and controls.

\begin{tabular}{cccc}
\hline & Patients & Controls & P value \\
\hline No. & 100 & 75 & $>0.05$ \\
Age: (mean + SD)year & $34.2 \pm 8.5$ & $30.1 \pm 9.7$ & $>0.05$ \\
Gender: No. (\%) & & & $39(52)$ \\
Male & $54(54)$ & $36(48)$ & \\
\hline
\end{tabular}

Table 2. H. Pylori titer in study population.

\begin{tabular}{|c|c|c|c|}
\hline \multirow{2}{*}{ Investigations } & Patients & Controls & \multirow{2}{*}{$P$ value } \\
\hline & Mean \pm SD & Mean \pm SD & \\
\hline H. Pylori IgG (Au/ml) & $68.4 \pm 37.5$ & $5.9 \pm 0.99$ & $<0.01$ \\
\hline H. Pylori IgA (Ndx) & $1.9 \pm 1.4$ & $0.60 \pm 0.38$ & $<0.01$ \\
\hline
\end{tabular}

Table 3. Lipid profile in study population.

\begin{tabular}{cccc}
\hline \multirow{2}{*}{ Lipid profile (mg/dl) } & Patients & Controls & \multirow{2}{*}{ P value } \\
\cline { 2 - 3 } & Mean \pm SD & Mean \pm SD & $<0.01$ \\
LDL & $97.8 \pm 26.6$ & $78.2 \pm 11.3$ & $<0.01$ \\
HDL & $40.6 \pm 8.7$ & $59.08 \pm 9.3$ & $<0.01$ \\
T. cholestrol & $172.8 \pm 30.5$ & $143.7 \pm 25.6$ & $<0.01$ \\
\hline
\end{tabular}

Table 4. H. Pylori titer and Carotid thickness (CIMT) in study population.

\begin{tabular}{ccc}
\hline & Patients & Controls \\
\cline { 2 - 3 } Carotid thickness $(\mathbf{m m})$ & Mean \pm SD & Mean \pm SD \\
\hline ICA & $0.6 \pm 0.16$ & $0.45 \pm 0.08$ \\
CCA & $0.6 \pm 0.18$ & $0.49 \pm 0.07$ \\
\hline
\end{tabular}

Table 5. Relationship between H. Pylori IgG level and lipid profile, Carotid thickness in patients.

\begin{tabular}{ccc}
\hline Investigations & Correlation coefficient $(\mathbf{r})$ & P value \\
\hline LDL $(\mathrm{mg} / \mathrm{dl})$ & 0.230 & $<0.01$ \\
HDL $(\mathrm{mg} / \mathrm{dl})$ & -0.258 & $<0.01$ \\
S. Cholesterol (mg/dl) & 0.249 & $<0.05$ \\
TG (mg/dl) & 0.031 & $>0.05$ \\
ICA (mm) & 0.532 & $<0.01$ \\
CCA (mm) & 0.456 & $<0.01$ \\
\hline
\end{tabular}

LDL-C and decrease of HDL-C levels of infected people creates an atherogenic lipid profile which could promote atherosclerosis with its complications [12]. While Akbas et al., reported that there was no significant differences in serum HDL-C, LDL-C and T. cholesterol level while serum TG levels of $H$. pylori positive subjects were significantly higher than those of $H$. pylori negative subjects [22]. These differences can be explained by different genetic factors, and type of the sample.

Previous studies have indicated that serum triglyceride and HDL-C levels can change during the acute phase of bacterial infection [23] [24]. These alterations promote atherogenesis, which have been attributed to the action of bacterial lipopolysacchride (LPS) [24]. Volanen expressed that the administration of endotoxin (LPS) induces the production of several cytokines, such as tumor necrosis factor (TNF- $\alpha$ ) which increases serum trig- 
lyceride level in animals. They have also suggested that changes in lipid profile seem to be related to the production of inflammatory cytokines by cells chronically infected with Gram-negative bacteria [24].

There is considerable evidence suggesting that ultrasonic measurements of early atherosclerosis are clinically significant. In prospective studies increased IMT has been related to an increased risk of cardiovascular diseases [25] [26]. There is conflicting data regarding CIMT and H. pylori infection. Some researchers have reported no relationship between $H$. pylori and CIMT [27] [28]. However, Akbas et al. reported the mean and maximum values of right and overall CIMT were significantly increased in $H$. pylori positive subjects compared with negative subjects [22]. Mete et al. reported that the right, the left and the mean CIMT were significantly higher in $H$. pylori positive group versus $H$. pylori negative group and these finding support our results [29].

We found a high correlation between H. Pylori IgG level and HDL level, carotid thickness $(\mathrm{p}<0.01)$, and a moderate correlation between the level of H. Pylori IgG and T. cholesterol, LDL-cholesterol and triglyceride level. Those may be explained by several hypotheses to describe the mechanisms of this relationship with direct or indirect effects. $H$. pylori is a bacterium with effects like endothelial injury, smooth muscle proliferation, and local inflammation on the vascular wall. This bacterium has also indirect effects as proinflammatory, procoagulant, and atherogenic action; these can change risk factors (lipid profile, coagulation, levels of oxidative metabolites), production of cross-reactive antibodies, malabsoprtion of nutrients and vitamins, and metabolic factors such as overproduction of ammonia [30].

Acute and chronic infections causing the inflammation of arteries may promote the atherosclerotic cascade, induces a long standing low-grade persistent inflammation stimulus [31].

\section{Conclusion}

H. pylori infected people have increased CIMT and T. cholestrol, TG and LDL-C and decreased HDL-C levels that create an atherogenic lipid profile which could promote atherosclerosis.

\section{Competing Interests}

None.

\section{References}

[1] Eckardstein, A.V. (2004) Is There a Need for Novel Cardiovascular Risk Factors? Nephrology Dialysis Transplantation, 19, 761-765. http://dx.doi.org/10.1093/ndt/gfh111

[2] Greenland, P., Knoll, M.D. and Stamler, J. (2003) Major Risk Factors as Antecedents of Fatal and Nonfatal Coronary Heart Disease Events. JAMA, 290, 891-897. http://dx.doi.org/10.1001/jama.290.7.891

[3] Kastelein, J.J., Wiegman, A. and Groot, E. (2003) Surrogate Markers of Atherosclerosis: Impact of Statins. Atherosclerosis Supplements, 4, 31-36. http://dx.doi.org/10.1016/S1567-5688(03)00007-2

[4] Watt, S., Aesch, B., Lanotte, P., Tranquart, F. and Quentin, R. (2003) Viral and bacterial DNA in Carotid Atherosclerotic Lesions. European Journal of Clinical Microbiology \& Infectious Diseases, 22, 99-105.

[5] Hamed, S.A., Amine, N.F., Galal, G.M., Helal, S.R., El-Din, L.M.T., Shawky, O.A., et al. (2008) Vascular Risks and Complications in Diabetes Mellitus. The Role of Helicobacter pylori Infection. Journal of Stroke \& Cerebrovascular Diseases, 17, 86-94. http://dx.doi.org/10.1016/j.jstrokecerebrovasdis.2007.10.006

[6] Cammaroat, G., Pasceri, V., Gasbarrini, A. and Gabarrini, G. (2000) Helicobacter pylori Is an Aetiologic Factor for Ischaemic Heart Disease: The Case against. Digestive and Liver Disease, 32, 65-68. http://dx.doi.org/10.1016/S1590-8658(00)80047-X

[7] Franceschi, F., Navarese, E.P., Mollo, R., Giupponi, B., De Marco, G., Merra, G., Gasbarrini, G. and Silveri, N.G. (2009) Helicobacter pylori and Atherosclerosis. A Review of the Literature. Recenti Progressi in Medicina, 100, 91-96.

[8] Gen, R., Demir, M. and Ataseven, H. (2010) Effect of Helicobacter pylori Eradication on Insulin Resistance, Serum Lipids and Low-Grade Inflammation. Southern Medical Journal, 103, 190-196. http://dx.doi.org/10.1097/SMJ.0b013e3181cf373f

[9] Khairy, P., Rinfret, S., Tardif, J.C., Marchand, R., Shapiro, S., Brophy, J., et al. (2003) Absence of Association between Infectious Agents and Endothelial Function in Healthy Young Men. Circulation, 107, 1966-1971. http://dx.doi.org/10.1161/01.CIR.0000064895.89033.97

[10] Chimienti, G., Russo, F. and Lamanuzzi, B.L. (2003) Helicobacter pylori Is Associated with Modified Lipid Profile: 
Impact on Lipoprotein (a). Clinical Biochemistry, 36, 359-365. http://dx.doi.org/10.1016/S0009-9120(03)00063-8

[11] Asano, K., Kubo, M., Yonemoto, K., Doi, Y., Ninomiya, T., Tanizaki, Y., et al. (2008) Impact of Serum Total Cholestrol on the Incidence of Gastric Cancer in a Population-Based Prospective Study: The Hisayama Study. International Journal of Cancer, 122, 909-914. http://dx.doi.org/10.1002/ijc.23191

[12] Buzás, G.M. (2014) Metabolic Consequences of Helicobacter pylori Infection and Eradication. World Journal of Gastroenterology, 20, 5226-5234. http://dx.doi.org/10.3748/wjg.v20.i18.5226

[13] Pellicano, R., Broutet, N., Ponzetto, A. and Mégraud, F. (1999) Helicobacter pylori: From the Stomach to the Heart. European Journal of Gastroenterology \& Hepatology, 11, 1335-1337. http://dx.doi.org/10.1097/00042737-199911000-00027

[14] Jia, E.Z., Zhao, F.J., Hao, B., Zhu, T.B., Wang, L.S., Chen, B., et al. (2009) Helicobacter pylori Infection Is Associated with Decreased Serum Levels of High Density Lipoprotein, but Not with the Severity of Coronary Atherosclerosis. $\mathrm{Li}$ pids in Health and Disease, 8, 59. http://dx.doi.org/10.1186/1476-511X-8-59

[15] Hoffmeister, A., Rothenbacher, D., Bode, G., Persson, K., März, W., Nauck, M.A., et al. (2001) Current Infection with Helicobacter pylori, but Not Seropositivity to Chlamydia pneumonia or Cytomegalovirus, Is Associated with Atherogenic, Modified Lipid Profile. Arteriosclerosis, Thrombosis, and Vascular Biology, 21, 427-432. http://dx.doi.org/10.1161/01.ATV.21.3.427

[16] Mackness, M., Durrington, P. and Mackness, B. (2004) Paraoxonase 1 Activity, Concentration and Genotype in Cardiovascular Disease. Current Opinion in Lipidology, 15, 399-404. http://dx.doi.org/10.1097/01.mol.0000137227.54278.29

[17] Georges, J.L., Rupprecht, H.J., Blankenberg, S., Poirier, O., Bickel, C., Hafner, G., et al. (2003) Impact of Pathogen Burden in Patients with Coronary Artery Disease in Relation to Systemic Inflammation and Variation in Genes Encoding Cytokines. American Journal of Cardiology, 92, 515-521.http://dx.doi.org/10.1016/S0002-9149(03)00717-3

[18] Karpouza, A., Samouilidou, E., Karagiannis, S., Kostopoulou, V., Sotiropoulou, M., Roma, E., et al. (2008) Patients with Duodenal Ulcer Have Lower Levels of Serum Cholesterol Compared to Other Dyspeptic Patients Independently of Helicobacter pylori Status. Scandinavian Journal of Gastroenterology, 43, 922-928. http://dx.doi.org/10.1080/00365520802008132

[19] Kucukazman, M., Yavuz, B., Sacikara, M., Asilturk, Z., Ata, N., Ertugrul, D.T., et al. (2009) The Relationship between Updated Sydney System Score and LDL Cholesterol Levels in Patients Infected with Helicobacter pylori. Digestive Diseases and Sciences, 54, 604-607. http://dx.doi.org/10.1007/s10620-008-0391-y

[20] Satoh, H., Saijo, Y., Yoshioka, E. and Tsutsui, H. (2010) Helicobacter Pylori Infection Is a Significant Risk for Modified Lipid Profile in Japanese Male Subjects. Journal of Atherosclerosis and Thrombosis, 17, 1041-1048. http://dx.doi.org/10.5551/jat.5157

[21] Kim, H.L., Jeon, H.H., Park, I.Y., Choi, J.M., Kang, J.S. and Min, K.W. (2011) Helicobacter pylori Infection Is Associated with Elevated Low Density Lipoprotein Cholesterol Levels in Elderly Koreans. Journal of Korean Medical Science, 26, 654-658. http://dx.doi.org/10.3346/jkms.2011.26.5.654

[22] Akbas, H.S., Basyigit, S., Suleymanlar, I., Kemaloglu, D., Koc, S., Davran, F., et al. (2010) The Assessment of Carotid Intima Media Thickness and Serum Paraoxonase-1 Activity in Helicobacter pylori Positive Subjects. Lipids in Health and Disease, 9, 92.

[23] Feingold, K.R., Hardardottir, I., Memon, R., Krul, E.J., Moser, A.H., Taylor, J.M., et al. (1993) Effect of Endotoxin on Cholesterol Biosynthesis and Distribution in Serum Lipoproteins in Syrian Hamsters. Journal of Lipid Research, 34, 2147-2158.

[24] Volanen, I., Raitakari, O.T., Vainionpää, R., Arffman, M., Aarnisalo, J., Anglé, S., et al. (2005) Serum Lipid Profiles Poorly Correlate with Chlamydia Pneumoniae, Helicobacter pylori, and Cytomegalovirus Seropositivity in Prospectively Followed-Up Healthy Children. Arteriosclerosis, Thrombosis, and Vascular Biology, 25, 827-832. http://dx.doi.org/10.1161/01.ATV.0000158382.50942.6a

[25] Gupta, N., Saigal, R., Goyal, L., Agrawal, A., Bhargava, R. and Agrawal, A. (2014) Carotid Intima Media Thickness as a Marker of Atherosclerosis in Ankylosing Spondylitis. International Journal of Rheumatology, 2014, Article ID: 839135. http://dx.doi.org/10.1155/2014/839135

[26] Katakami, N., Kaneto, H. and Shimomura, I. (2014) Carotid Ultrasonography: A Potent Tool for Better Clinical Practice in Diagnosis of Atherosclerosis in Diabetic Patients. Journal of Diabetes Investigation, 5, 3-13. http://dx.doi.org/10.1111/jdi.12106

[27] Altintas, E., Ucbilek, E., Ulu, O., Sezgin, O., Uzer, C., Tataroglu, C. and Camdeviren, H. (2007) Helicobacter pyloriAssociated Atrophic Gastritis and Carotid Intima-Media Thickness, Is There a Link? International Journal of Clinical Practice, 61, 810-814. http://dx.doi.org/10.1111/j.1742-1241.2006.01133.x

[28] Folsom, A.R., Nieto, F.J., Sorlie, P., Chambless, L.E. and Graham, D.Y. (1998) Helicobacter pylori Seropositivity and 
Coronary Heart Disease Incidence. Circulation, 98, 845-850. http://dx.doi.org/10.1161/01.CIR.98.9.845

[29] Mete, R., Oran, M., Alpsoy, S., Gunes, H., Tulubas, F., Turan, C., et al. (2013) Carotid Intima-Media Thickness and Serum Paraoxonase-1 Activity in Patients with Helicobacter pylori. European Review for Medical and Pharmacological Sciences, 17, 2884-2889.

[30] Kanbay, M., Gür, G., Yücel, M., Yilmaz, U. and Boyacioĝlu S. (2005) Does Eradication of Helicobacter pylori Infection Help Normalize Serum Lipid and CRP Levels? Digestive Diseases and Sciences, 50, 1228-1231. http://dx.doi.org/10.1007/s10620-005-2764-9

[31] Van Lent, F. (2000) Markers of Inflammation as Predictors in Cardiovascular Disease. Clinica Chimica Acta, 293, 3152. http://dx.doi.org/10.1016/S0009-8981(99)00236-3 
Scientific Research Publishing (SCIRP) is one of the largest Open Access journal publishers. It is currently publishing more than 200 open access, online, peer-reviewed journals covering a wide range of academic disciplines. SCIRP serves the worldwide academic communities and contributes to the progress and application of science with its publication.

Other selected journals from SCIRP are listed as below. Submit your manuscript to us via either submit@scirp.org or Online Submission Portal.
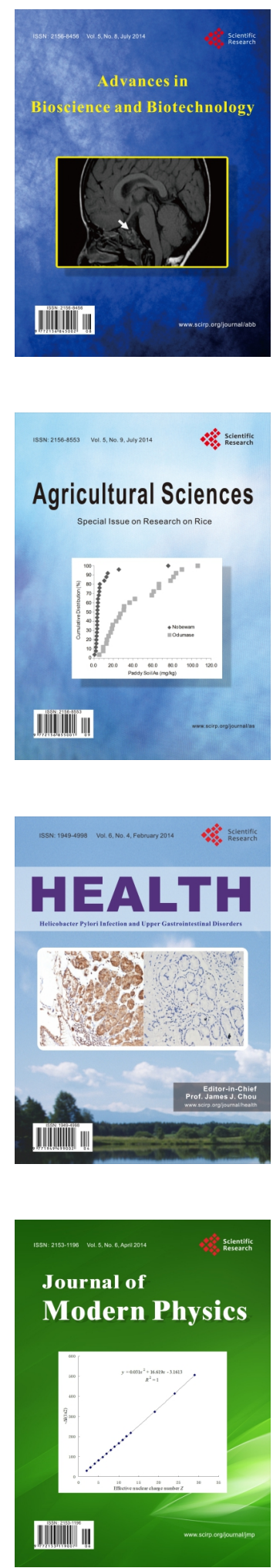
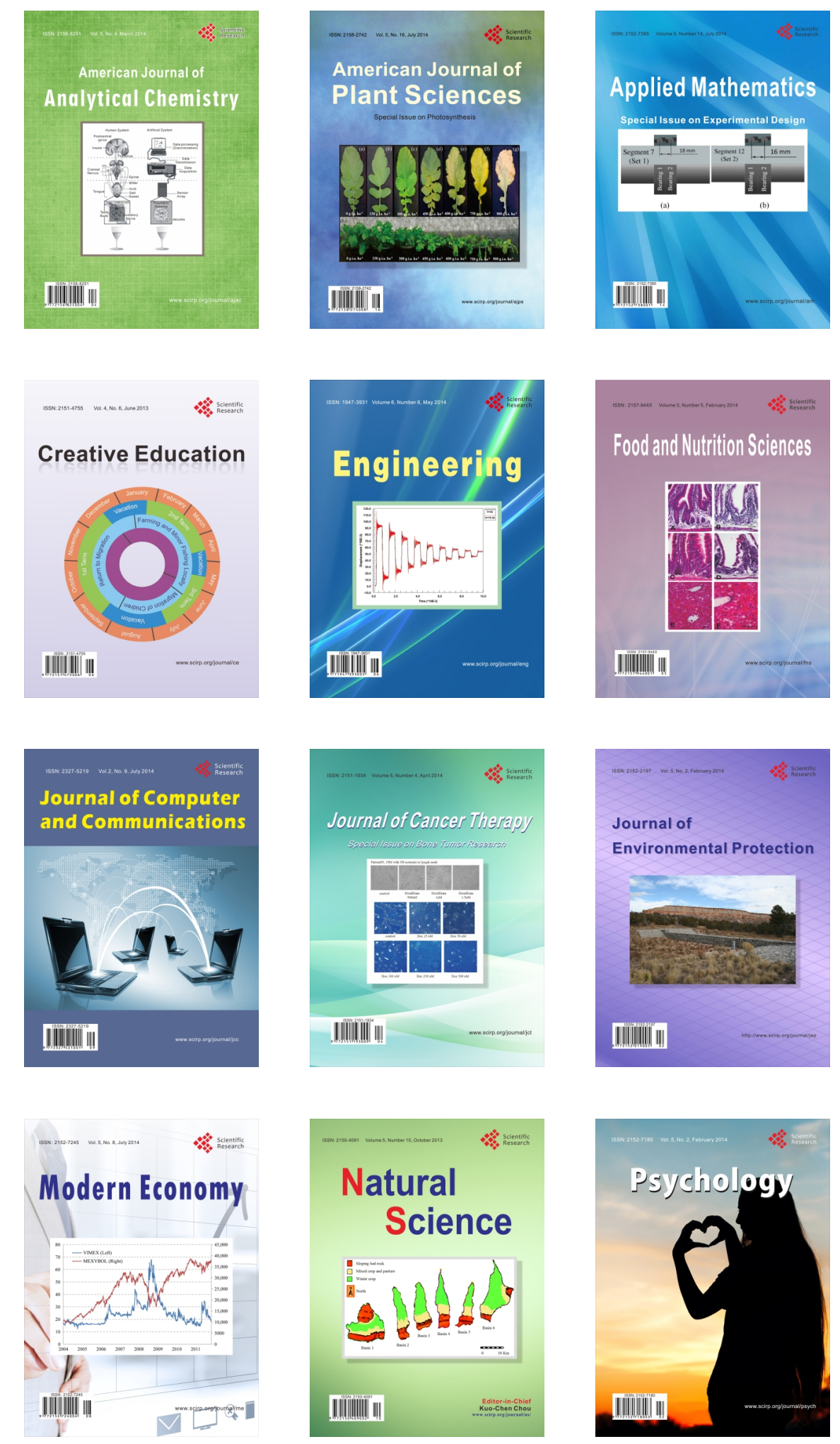